\title{
Optimization of extraction conditions of phytochemical compounds in "Xiem" banana peel powder using response surface methodology
}

\author{
Ngo Van Tai (D), Mai Nhat Linh, Nguyen Minh Thuy* (D) \\ Department of Food Technology, College of Agriculture, Can Tho University, Can Tho, Vietnam.
}

\begin{tabular}{l}
\hline ARTICLE INFO \\
\hline Article history: \\
Received on: June 07, 2021 \\
Accepted on: August 13, 2021 \\
Available online: November 10, 2021
\end{tabular}

Key words:

"Xiem" banana peels, antioxidant compounds, extraction,

optimization, response surface methodology

\begin{abstract}
In Vietnam, banana is a popular fruit that is grown and consumed as a ripe fruit or used for cooking. During industrial processing, its peel is removed as a waste product (about $18 \%-33 \%$ of the whole fruit) containing many bioactive compounds useful for human health. The aim of this study was to determine the effects of extraction conditions such as the ratio of solvent to solid $(\mathrm{ml} / \mathrm{g})$, extraction temperature $\left({ }^{\circ} \mathrm{C}\right)$, and extraction time (minutes) on extraction yield such as total polyphenol and flavonoid contents (TPC and TFC, respectively). The response surface methodology and Box-Behnken design were used to optimize the extraction of antioxidant compounds from "Xiem" banana peels cultivated in U Minh district, Cà Mau province, Vietnam. The results showed that the most important variable in the extraction process was solvent concentration. Optimal conditions were found to be $60 \%, 76: 1,68^{\circ} \mathrm{C}$, and 48 minutes for solvent concentration, solvent-to-solid ratio, temperature, and time, respectively, resulting in the maximum TPC and TFC, $62.41 \mathrm{mgGAE} / \mathrm{g}$ and $6.98 \mathrm{mgQE} / \mathrm{g}$, respectively.
\end{abstract}

\section{INTRODUCTION}

Vietnam is known for its rich biodiversity, with many nutritious tropical fruits easily found in the Mekong Delta region. Banana (Musa species) is a popular and nutritious tropical fruit and is produced and consumed yearly in our country, and it is an important crop in subtropical and tropical regions which provide a great source of nutrients and energy. Bananas are generally classified as "dessert" sweet bananas, which are cooked and eaten raw but can also be eaten when fully ripe [1]. The main by-product of bananas is the peel, which accounts for $18 \%-30 \%$ of the whole fruit [2]. Several recent studies reported that banana peel contained potential antioxidant compounds such as vitamin A, vitamin $\mathrm{C}$, carotenoids, and phenolic compounds, which are the most abundant antioxidants in the pulp of bananas as well as in banana peels [3]. Banana peel is also known to have higher antioxidant activity than banana pulp [4,5], containing high antioxidant capacity, such as phenolic compounds, anthocyanins, carotenoids, catecholamines, sterols, and triterpenes [6]. Preliminary studies suggested that it has a large amount of phenolic compounds and

*Corresponding Author

Nguyen Minh Thuy, Department of Food Technology, College of Agriculture, Can Tho University, Can Tho, Vietnam.E-mail:nmthuy@ ctu.edu.vn potent antioxidant properties, which may contribute to the plant's medicinal properties. Moreover, it may be used for medicinal purposes or functional food products.

Extraction plays an important role in the production and purification of bioactive compounds from plant materials and by-products [7]. Some phytochemical extraction techniques can be divided into three groups, that is, traditional, innovative, or a combination of these two techniques. The extraction efficiency of antioxidant compounds depends on several factors including extraction method, time, temperature, sample size, sample texture, solvent type and concentration, $\mathrm{pH}$, ratio of sample and solvent, and the diffusivity of the solvent in the materials [8-10]. Due to the complexity of the structure and properties of the bioactive compounds and the structure of the extracted materials, no universal extraction procedure is available [11]. The effect of extraction parameters on extraction yield of phytochemicals was reported for different plant materials, for example, the effect of extraction conditions on the yield of catechin extracts from green tea leaves [12] and tiger nut by-products [13]. The study on extracting polyphenol content and antioxidant capacity from orange peels showed an important influence of temperature [14]. In fact, it is also necessary to have separate extraction parameters for each type of material due to the difference and diversity in phytochemical content [15]. 
The response surface methodology (RSM) was used to evaluate the effects of several process variables and their interactions [16]. RSM is a set of statistical and mathematical techniques useful for developing, improving, and optimizing processes, whereas the response of interest is influenced by a number of factors (independent variables). RSM not only determines the effect of the independent variables but also creates a mathematical model that describes chemical or biochemical processes [17]. There have been very few previous studies on the effect of solvents and extraction parameters on the extraction yield of phenolic compounds and antioxidants from banana peels. The selection of the appropriate extraction solvent is an overlooked variable for extraction efficiency and ending applications. According to the Food and Drug Administration, there are a number of solvents that are permitted for use in the food and pharmaceutical sectors [18], because of toxic solvent residues in the extracts.

In the present study, a dual solvent system of ethanol and water was applied with the consideration for the future use of the extracts as dietary supplements or food preservatives. Therefore, the aim of this study was to investigate the effects of different solvents which are allowed to be applied in the food and pharmaceutical fields and to determine the influence of optimizing the extraction parameters using conventional solvent techniques to maximize the recovery of antioxidant compounds from banana peel.

\section{MATERIALS AND METHODS}

\subsection{Sample Preparation}

Banana peels are obtained from the processing of banana products with simultaneous research in our laboratory. It is washed thoroughly with tap water, then chopped, and soaked in sodium metabisulfite $(500 \mathrm{ppm})$. The peels were dried at $60^{\circ} \mathrm{C}$ until the moisture content was less than $12 \%$. The dried peel was ground into a fine powder and sieved. Finally, the obtained powder was packed in vacuum PA bags and stored at room temperature $(28 \pm$ $2^{\circ} \mathrm{C}$ ) for further use.

This study was conducted from June 2020 to May 2021 at the Department of Food Technology, Can Tho University, Vietnam.

\subsection{Chemicals and Reagents}

Gallic acid, quercetin, and Folin-Ciocalteu were purchased from Sigma-Aldrich (MO). The deionized water and other chemicals used in this study were of analytical reagent grade.

\subsection{Optimization of Extraction Process}

Dried samples $(2 \mathrm{~g})$ were used for extraction. The optimization of the extraction process was designed using the Box-Behnken design according to the RSM [17] with six center runs that were used, giving a total of 18 experimental runs. Each factor was surveyed with three levels, coded as $-1,0$, and +1 . The dependent variables (responses) analyzed were TPC and TFC of product. The levels of variables are shown in Table 1 . The transparent extracts were obtained by filtering (Whatman No. 4 filter paper) and then TPC and TFC of the extracts were analyzed.
Table 1: Experimental range and levels of the independent variables.

\begin{tabular}{lccc} 
Variables (extraction parameter) & \multicolumn{3}{c}{ Levels of code } \\
A: solvent to solid ratio $(\mathrm{ml} / \mathrm{g})$ & 50 & 70 & $\mathbf{0}$ \\
B: extraction time (minutes) & 30 & 45 & 60 \\
C: extraction temperature $\left({ }^{\circ} \mathrm{C}\right)$ & 60 & 70 & 80 \\
\hline
\end{tabular}

\subsection{Determination of TPC}

The Folin-Ciocalteu assay was used for this method [19]. The absorbance of the reaction solution containing a polyphenol compound extracted from banana peel and reagent was measured at $738 \mathrm{~nm}$. TPC was calculated as $\mathrm{mg}$ gallic acid equivalent per gram sample (mgGAE/g) through a standard curve obtained $(y=$ $\left.0.0025 x+0.0632, R^{2}=0.9957\right)$.

\subsection{Determination of TFC}

The reaction between the flavonoid compounds in the extract with aluminum chloride (10\%) formed a yellow solution, which was recorded at $415 \mathrm{~nm}$ [20]. Results are based on a standard curve measured at the same wavelength $\left(y=0.1273 x-0.7303, R^{2}=\right.$ $0.9903)$. TFC is calculated as $\mathrm{mg}$ of quercetin equivalent per gram sample (mgQE/g).

\subsection{Statistical Analysis}

The Statgraphics Centurion XV.I application was used to fit the model to the observed data using the RSM. The effect of the independent variables on the model for response $(Y)$ is shown in

$Y=b+b_{1} A+b_{2} B+b_{3} C+b_{4} A B+b_{5} A C+b_{6} B C+b_{7} A^{2}+b_{8} B^{2}+$ $b_{9} C^{2}$

where $A, B$, and $C$ are independent variables and $b, b_{1}, b_{2}, \ldots b_{9}$ are offset, interaction, and squared effects. The selection model was mainly based on the $R^{2}$ value obtained from the regression.

\section{RESULTS AND DISCUSSION}

\subsection{Solvent Selection for Extraction}

This extraction mainly uses a solvent to separate the desired components from the plant cells. Makasana et al. [21] showed that the maximum solvent extraction efficiency was achieved when solvent mixtures, especially alcohol mixed with water, were used. It could be explained that when ethanol:aqueous solvent was applied, the water caused some plant components to expand and soften, and ethanol can be easily exposed in the plant matrix thereby increasing the extractability. The obtained results showed that a $60 \%$ ethanol concentration showed high extraction efficiency of biological compounds in banana peel extract (Table 2). At higher concentrations, perhaps because the amount of water was not enough to soften the cell walls, the extraction efficiency was markedly reduced. In addition, since ethanol has a lower boiling point and is safe for human consumption and it can also be easily evaporated during extraction, a $60 \%$ ethanol concentration was chosen for further experiments. 
Table 2: Extraction TPC and TFC yield of banana peel.

\begin{tabular}{lcc} 
Solvents & TPC $(\mathbf{m g G A E} / \mathbf{g})$ & TFC $(\mathbf{m g Q E} / \mathbf{g})$ \\
Water & $50.21 \pm 0.87$ & $5.11 \pm 0.09$ \\
Water-ethanol (80\%-20\%) & $52.14 \pm 0.67$ & $5.67 \pm 0.12$ \\
Water-ethanol (60\%-40\%) & $58.13 \pm 0.66$ & $6.03 \pm 0.18$ \\
Water-ethanol (40\%-60\%) & $62.42 \pm 0.56$ & $6.67 \pm 0.21$ \\
Water-ethanol (20\%-80\%) & $57.13 \pm 0.43$ & $6.12 \pm 0.11$ \\
Ethanol absolute & $53.23 \pm 0.23$ & $5.87 \pm 0.15$ \\
\hline
\end{tabular}

Values are expressed as mean \pm standard deviation.

\subsection{Optimization of Extraction Process}

The three factors that greatly affected the extraction process of banana peel powder are temperature, time, and material/ solvent ratio. The efficiency of the process was assessed by total polyphenol content (mgGAE/g) and total flavonoid content (mgQE/g). The optimization process was carried out according to the RSM. In the optimization process, the independent variables of extraction temperature $(A)$, extraction time $(B)$, and solvent/solid ratio $(C)$ were measured with the levels according to the BoxBehnken model.

Optimization of the dried banana peel extraction process was performed with 18 runs and 3 repetitions. The TPC and TFC obtained in the extract ranged from 46.01 to $62.88 \mathrm{mgGAE} / \mathrm{g}$ and from 5.54 to $7.44 \mathrm{mgQE} / \mathrm{g}$, respectively. Model fitting plays an important role in explaining the accuracy of the RSM mathematical models, predicting the optimal value of the variance and the interaction between the selected parameters. The regression models obtained using the RSM for analysis of variance are presented in Table 3. The coefficient of determination $\left(R^{2}\right)$ is a measure of goodness of fit [22]. This investigation revealed that the $R^{2}$ for TPC and TFC were 0.98 and 0.89 , respectively, indicating that $98 \%$ and $89 \%$ of the trial's TPC and TFC could match those predicted by the models accordingly. The RMSE value is a measure of the standard deviation of the prediction errors and the lack of fit is an indicator of the null hypothesis. The fit of the model was also evaluated through the $p$ value of lack of fit. A good correlation model should have a good fit between the actual data and the model's predictions; therefore, a model built with a statistically significant lack-of-fit test is desirable [23]. The lack of fit of the TPC and TFC models has a $p$ value $>0.05$ (Table 3 ), so the fit of the model is very high. In addition, the $p$ value, which represents the confidence level of the models, is significant because the $p$ value of the models is less than 0.05 , which further confirms the reliability of the models with predictive responses in the current study [24].

The standardized effects of each factor were shown in Figure 1. From Figure 1, it was seen that TPC and TFC under extraction using ethanol were significantly affected by linear, quadratic, and cross effects. The $p$ values of the independent variables, square variables, and interacting variables are less than 0.05 , expected for AC interaction for TFC.

The regression models were obtained using Equation 2 and 3.

$\mathrm{TPC}=-597.7+1.93 A+2.51 B+15.2 C-0.006 A^{2}-0.009 A B-$ $0.009 A C-0.007 B^{2}-0.017 B C-0.1 C^{2}$

$\mathrm{TFC}=-12.6+0.17 A+0.29 B+0.18 C-0.0009 A^{2}-0.0008 A B-$ $0.002 B^{2}-0.0008 B C-0.001 C^{2}$.

The response surface and main effects plot showed the interaction between TPC of banana peel powder extract and temperature, extraction time, and solvent/solid ratio (Figs. 2 and 3). At the appropriate time, temperature, and solvent/solid ratio parameters, the solvent dissolved the substances in the raw materials, which

Table 3: Analysis of variance for TPC and TFC.

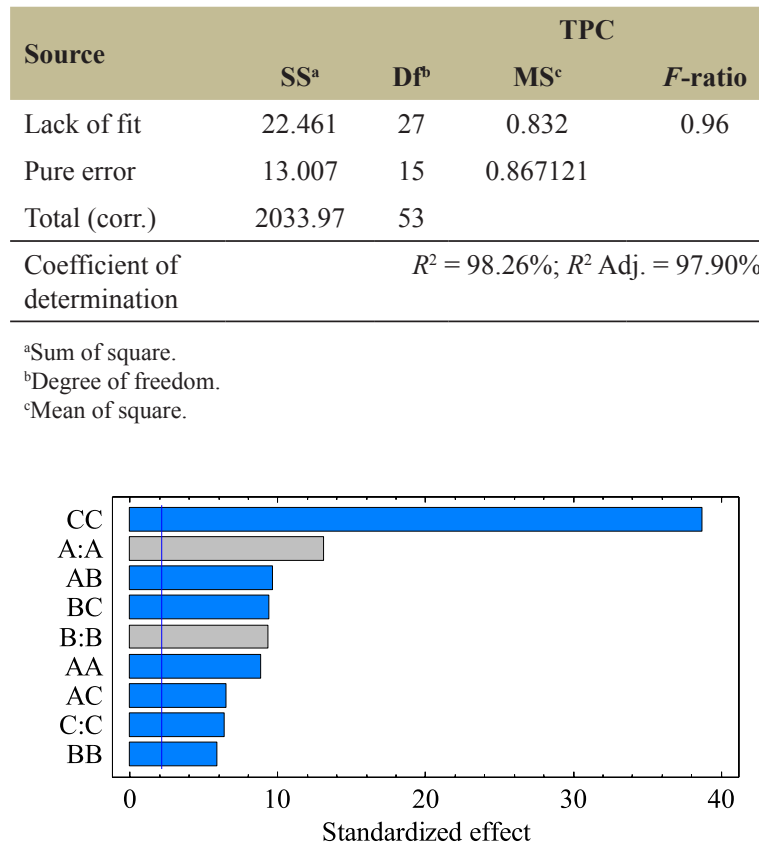

a)

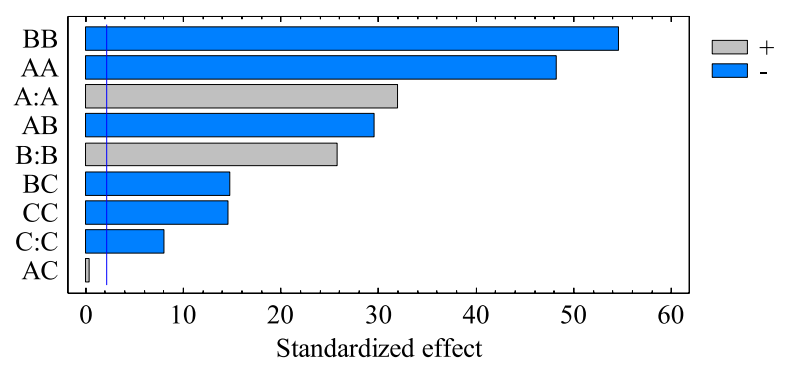

b)

Figure 1: Standardized Pareto charts for (a) TPC and (b) TFC. 


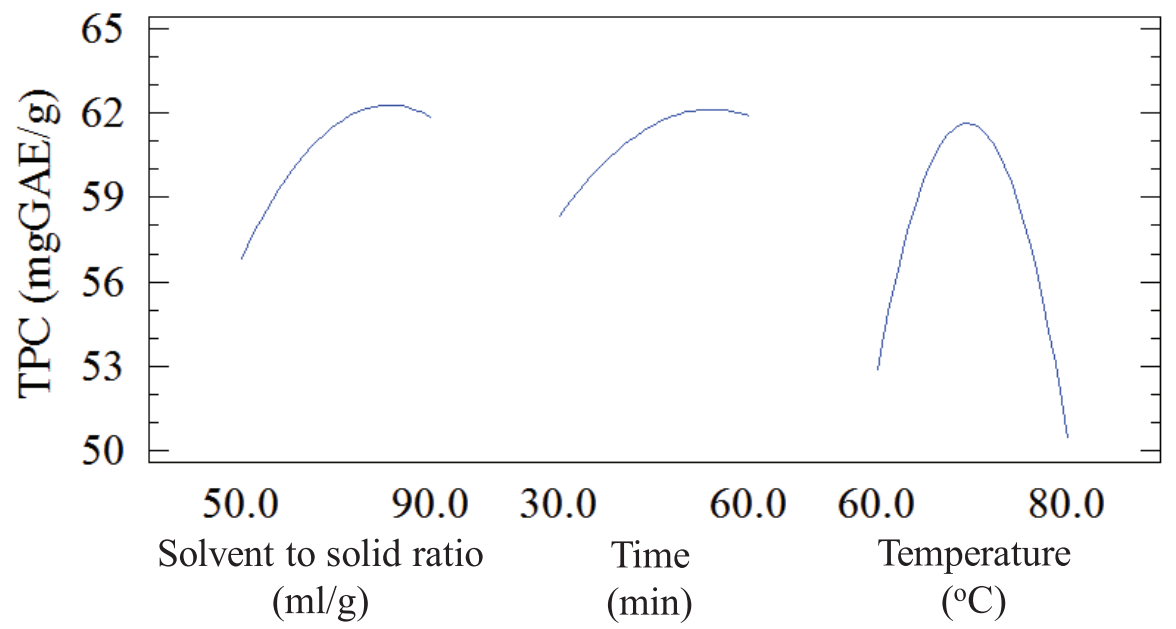

Figure 2: Main effects plot for TPC in extract.
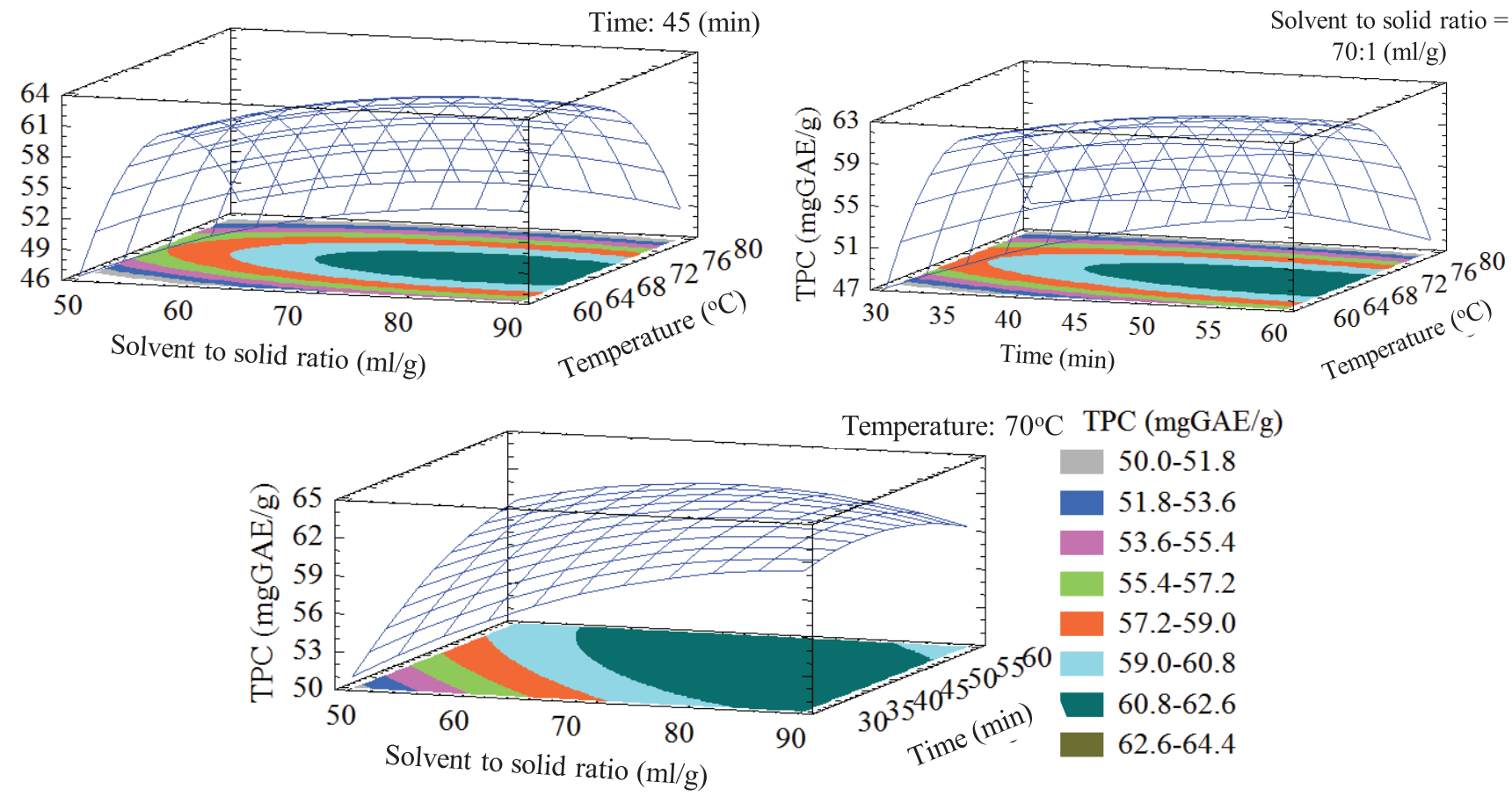

Figure 3: Estimated response surface plot for TPC in extract.

led to an increase in the total polyphenol content in the extract. TPC increases with an increasing extraction temperature, but when the temperature is too high, the content of biological compounds tends to decrease. When the extraction temperature increases, the solubility and diffusivity of polyphenol compounds and the conversion and wetting of the extracted material increase and the viscosity of the solvents decreases, resulting in the increase in the extraction efficiency of polyphenol compounds [8,25].

Extraction time had an effect on extraction efficiency. Polyphenol content increased with increasing extraction time. However, when the extraction time was too long, the extraction efficiency might be reduced due to oxidation decomposition. This can be explained by Fick's second law of diffusion: as the extraction time increases, the content of substances in the material diffuses from the cell to the outside [26]. However, the extraction yield of bioactive compounds would not increase after a certain time. This time interval depends on other extraction conditions such as solvent, extraction temperature, and material/solvent ratio as well as the nature of the material and compound to be extracted [27]. With a longer extraction time, the polyphenol compounds inside and outside the raw materials had almost reached equilibrium, so the extraction would be slowed down. In addition, these compounds could be oxidized by many factors from the extraction environment such as temperature, light, and oxygen [28]. Similarly, when the solvent/solid ratio increased, the polyphenol content also increased, and then it reached equilibrium before 


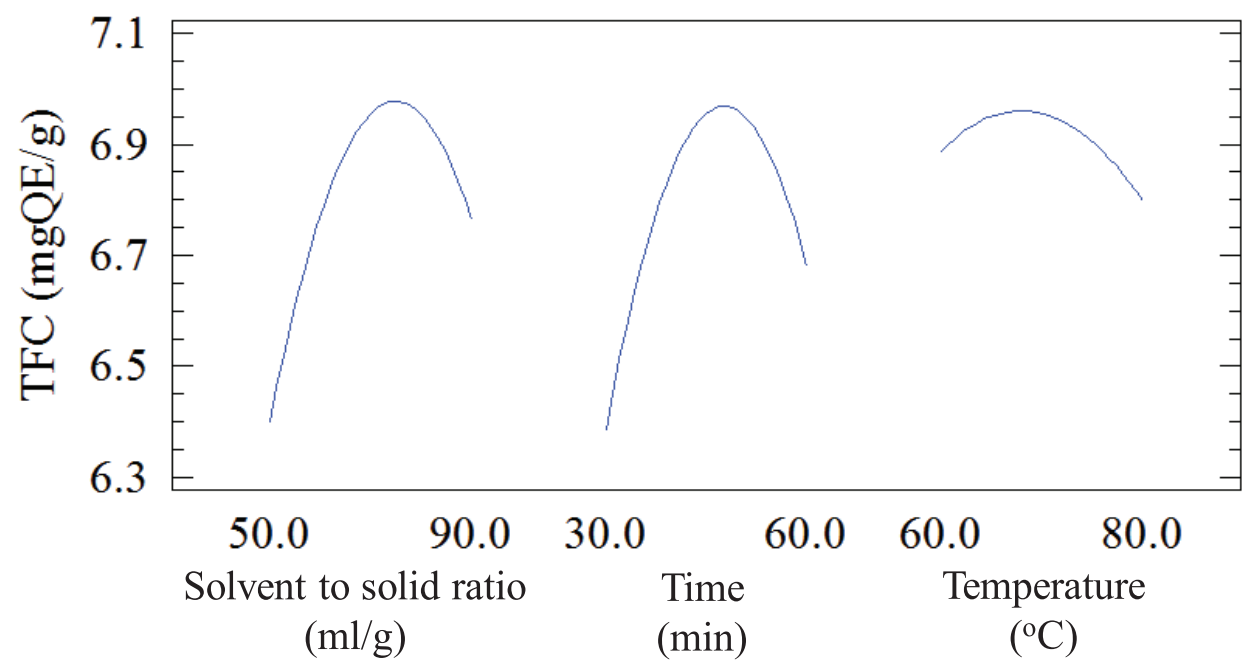

Figure 4: Main effects plot for TFC in extract.
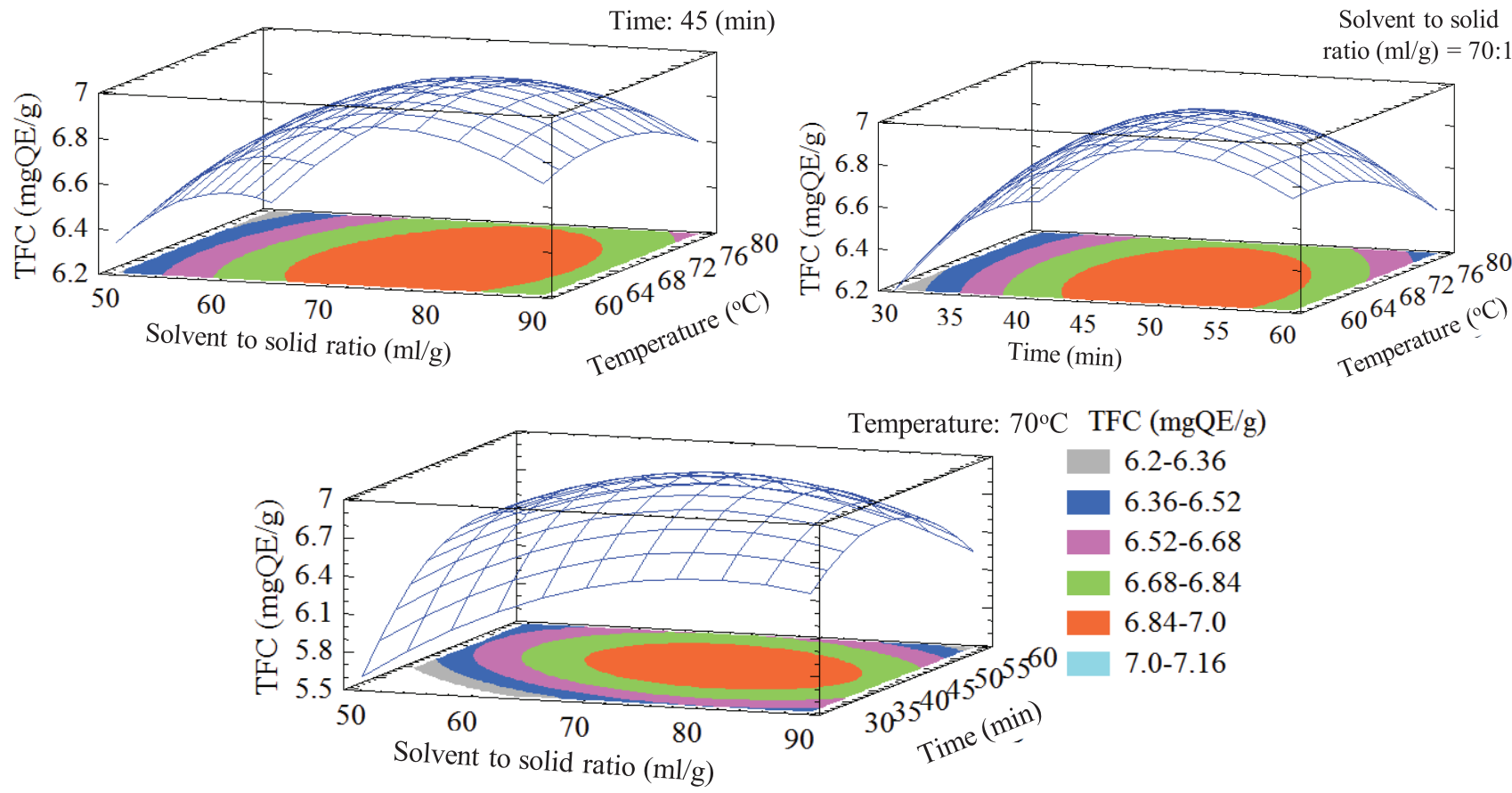

Figure 5: Estimated response surface plot for TFC in extract.

decreasing. Due to the increase in the ratio of solvent/solid, it led to the difference in the concentration gradient of the substances to be extracted in the raw materials with the extraction medium. The extraction efficiency decreased [29].

Similar to the trend of TPC under different extraction conditions, TFC increased with increasing extraction temperature and time, but when the extraction temperature and time were too high or too long, the content of bioactive compounds tended to decrease (Figs. 4 and 5). As mentioned above, polyphenols and flavonoids were well soluble in ethanol-containing solvents, and long-term/ high-temperature extraction could facilitate solvent penetration into the cell matrix of raw materials thereby improving the extraction yield. Oxidation could also occur which tends to reduce antioxidant compounds [30,31].

An overlay plot helps to identify combinations of experimental factors which simultaneously optimize some responses. It does so by maximizing the desired function. The goals for each response are currently set to maximize TPC and TFC. Based on the overlay plot in Figure 6, the optimal extraction conditions were found as $76: 1$ (solvent : solid, $\mathrm{ml} / \mathrm{g}$ ) at $68^{\circ} \mathrm{C}$ for 48 minutes. Under these conditions, the TPC and TFC of the extract were $62.41 \mathrm{mgGAE} / \mathrm{g}$ and $6.98 \mathrm{mgQE} / \mathrm{g}$, respectively. 

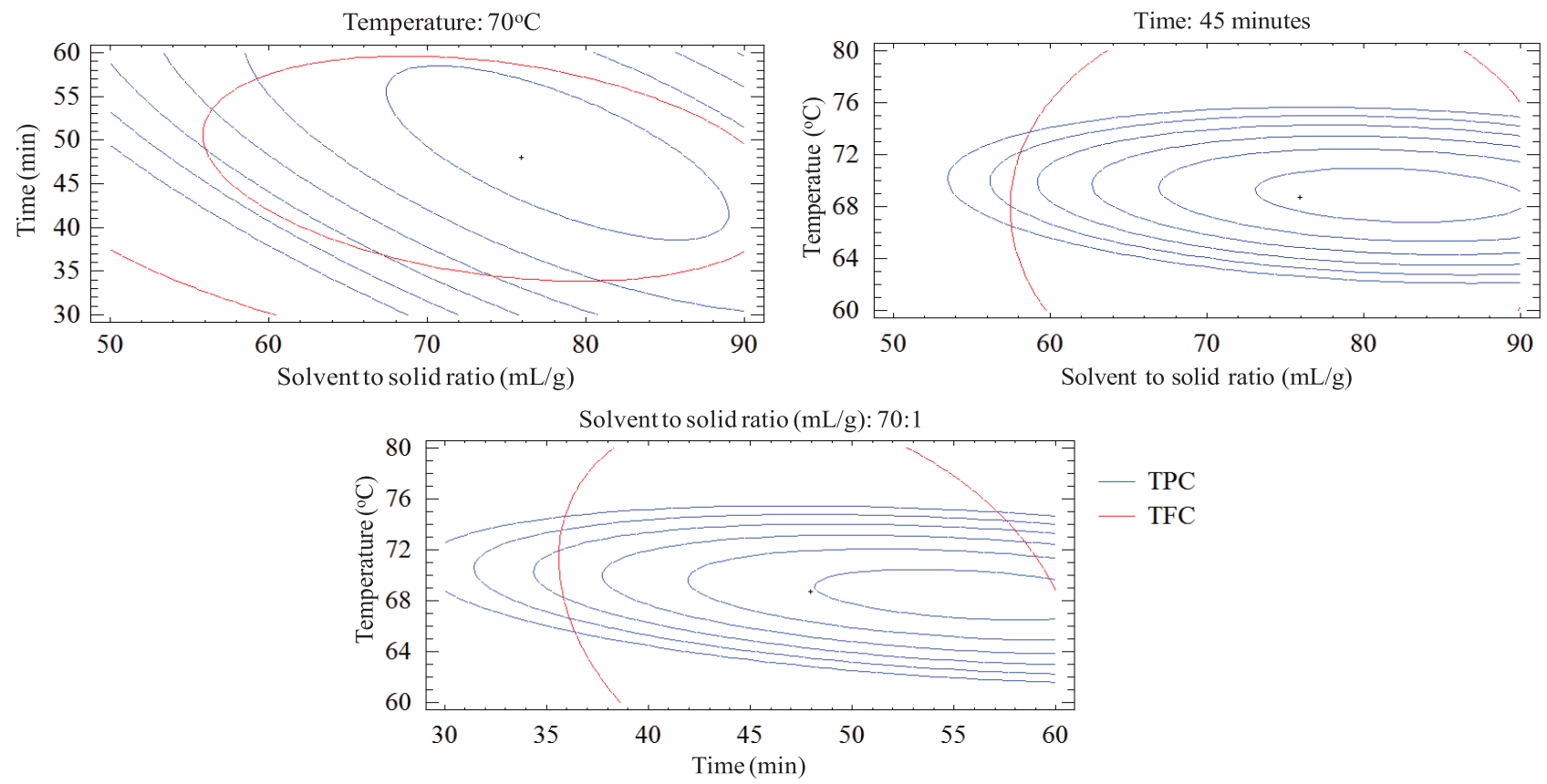

Figure 6: The overlay plot for TPC and TPC in extract at different conditions.

\section{CONCLUSION}

The RSM could be effectively and accurately applied in predicting TPC and TFC in banana peel extract. The obtained banana peel extract had high levels of TPC and TFC, which are substances with antioxidant activity, so in further research, it is recommended that the study should be applied to food/medical products as a source of natural antioxidants.

\section{ACKNOWLEDGMENT}

The authors acknowledge the financial support to Can Tho University, Vietnam from the Research fund project code number T2020-67.

\section{AUTHOR CONTRIBUTIONS}

All authors made substantial contributions to conception and design, acquisition of data, or analysis and interpretation of data; took part in drafting the article or revising it critically for important intellectual content; agreed to submit to the current journal; gave final approval of the version to be published; and agree to be accountable for all aspects of the work. All the authors are eligible to be an author as per the international committee of medical journal editors (ICMJE) requirements/guidelines.

\section{CONFLICTS OF INTEREST}

The authors report no financial or any other conflicts of interest in this work.

\section{ETHICAL APPROVAL}

This study does not involve experiments on animals or human subjects.

\section{PUBLISHER'S NOTE}

This journal remains neutral with regard to jurisdictional claims in published institutional affiliation.

\section{REFERENCES}

1. Perrier X, De Langhe E, Donohue M, Lentfer C, Vrydaghs L, Bakry $\mathrm{F}$, et al. Multidisciplinary perspectives on banana (Musa spp.) domestication. Proc Natl Acad Sci 2011;108(28):11311-8.

2. González-Montelongo R, Lobo MG, González M. Antioxidant activity in banana peel extracts: testing extraction conditions and related bioactive compounds. Food Chem 2010;119(3):1030-9.

3. Tsamo CVP, Herent MF, Tomekpe K, Emaga TH, Quetin-Leclercq $\mathrm{J}$, Rogez $\mathrm{H}$, et al. Phenolic profieling in the pulp and peel of nine plantain cultivars (Musa sp.). Food Chem 2015;167:197-204.

4. Oliveira L, Freire CSR, Silvestre AJ, Cordero N. Lipophilic extracts from banana fruit residues: a source of valuable phytosterols. J Agric Food Chem 2008;56:9520-5.

5. Pereira A, Maraschin M. Banana (Musa spp.) from peel to pulp: ethnopharmacology, source of bioactive compounds and its relevance for human health. J Ethnopharmacol 2008;160:149-63;doi:10.1021/jf801709t

6. Someya S, Yoshiki Y, Okubo K. Antioxidant compounds from bananas (Musa cavendish). Food Chem 2002;79:351-4.

7. Gan C, Latiff AA. Optimization of the solvent extraction of bioactive compounds from Parkia speciosa pod using response surface methodology. Food Chem 2011;124:1277-83.

8. Wang J, Sun B, Cao Y, Tian Y, Li X. Optimization of ultrasoundassisted extraction of phenolic compounds from wheat bran. Food Chem 2008;106(2):804-10.

9. Irakli M, Chatzopoulou P, Ekateriniadou L. Optimization of ultrasoundassisted extraction of phenolic compounds: oleuropein, phenolic acids, phenolic alcohols and flavonoids from olive leaves and evaluation of its antioxidant activities. Ind Crops Prod 2018;124:382-8.

10. Goltz C, Ávila S, Barbieri JB, Igarashi-Mafra L, Mafra MR Ultrasound-assisted extraction of phenolic compounds from Macela (Achyrolcine satureioides) extracts. Ind Crops Prod 2018;115:227-34. 
11. Thoo YY, Ho SK, Liang JY, Ho CW, Tan CP. Effects of binary solvent extraction system, extraction time and 12 extraction temperature on phenolic antioxidants and antioxidant capacity from mengkudu (Morinda citrifolia). Food Chem 2010;120:290-5.

12. Vuong QV, Golding JB, Stathopoulos CE, Nguyen MH, Roach PD. Optimizing conditions for the extraction of catechins from green tea using hot water. J Sep Sci 2011;34(21):3099-106.

13. Roselló-Soto E, Martí-Quijal FJ, Cilla A, Munekata PE, Lorenzo $\mathrm{JM}$, Remize $\mathrm{F}$, et al. Influence of temperature, solvent and $\mathrm{pH}$ on the selective extraction of phenolic compounds from tiger nuts byproducts: Triple-TOF-LC-MS-MS characterization. Molecules 2019;24(4):797.

14. Jeong SM, Kim SY, Kim DR, Jo SC, Nam KC, Ahn DU, et al. Effect of heat treatment on the antioxidant activity of extracts from citrus peels. J Agric Food Chem 2004;52(11):3389-93.

15. Wong YS, Sia CH, Khoo HE, Ang YK, Chang SK, Yim HS. Influence of extraction conditions on antioxidant properties of passion fruit (Passiflora edulis) peel. Acta Sci Pol Technol Aliment 2014;13(3):257-65.

16. Liyana-Pathirana C, Shahidi F. Optimization of extraction of phenolic compounds from wheat using response surface methodology. Food Chem 2005;93:47-56.

17. Myers RH, Montgomery DC, Anderson-Cook CM. Response surfacemethodology: process and product optimization using designedexperiments. John Wiley \& Sons, Hoboken, NJ, 2016.

18. Food and Drug Administration. Q3C-tables and list guidance for industry, 2017. Available via: https://www.fda.gov/media/71737/ download

19. $\mathrm{Fu} \mathrm{L}, \mathrm{Xu}$ BT, Xu XR, Gan RY, Zhang Y, Xia EQ, et al Antioxidant capacities and total phenolic contents of 62 fruits. Food Chem 2011;129(2):345-50.

20. Mandal B, Madan S. Preliminary phytochemical screening and evaluation of free radical scavenging activity of Stevia rebaudiana Bertoni from different geographical sources. J Pharmacogn Phytochem 2013;2 (1): 14-9.

21. Makasana J, Dholakiya BZ, Gajbhiye NA, Raju S. Extractive determination of bioactive flavonoids from butterfly pea (Clitoria ternatea Linn.). Rese Chem Intermed 2017;43:783-99.

22. Wang L, Wang Z, Li X. Optimization of ultrasonic-assisted extraction of phenolic antioxidants from Malus baccata (Linn.) Borkh. using response surface methodology. J Sep Sci 2013;36:1652-58.

23. Zabeti M, Daud WM, Aroua MK. Optimization of the activity of $\mathrm{CaO} / \mathrm{A} 12 \mathrm{O} 3$ catalyst forbiodiesel production using response surface method-ology. Appl Catal Gen 2009;366:154-9.

24. Mota I, Rodrigues Pinto PC, Novo C, Sousa G, Guerreiro O, Guerra $\mathrm{AR}$, et al. Extraction of polyphenolic compounds from Eucalyptus globulus bark: process optimization and screening for biological activity. Ind Eng Chem Res 2012;51:6991-7000.

25. Alfarsi MA, Lee CY. Optimization of phenolics and dietary fibre extraction from date seeds. Food Chem 2008;108:977-85.

26. Cracolice M, Peters E. Basics of introductory chemistry: anactive learning approach, Brooks/Cole, Pacific Grove, CA, 2009.

27. Silva EM, Souza JNS, Rogez H, Rees JF, Larondelle Y. Antioxidant activities and polyphenolic contents of fifteen selected plant species from the Amazonian region. Food Chem 2007;101:1012-8.

28. Naczk M, Shahidi F. Extraction and analysis of phenolics in food. J Chromatogr A 2004;1054(1-2):95-111.

29. Gertenbach D. Solid-liquid extraction technologies formanufacturing nutraceuticals. In: Mazza G, Maguer ML Shi J (Eds.). Functional foods: biochemical and processing aspects, CRC Press, Boca Raton, FL, pp 331-66, 2001.

30. Galvan d'Alessandro L, Kriaa K, Nikov I, Dimitrov K. Ultrasound assisted extraction of polyphenols from black chokeberry. Sep Purif Technol 2012;93:42-7.

31. Pingret D, Fabiano-Tixier AS, Chemat F. Degradation during application of ultrasound in food processing: a review. Food Control 2013;31:593-606.

How to cite this article:

Tai NV, Linh MN, Thuy NM. Optimization of extraction conditions of phytochemical compounds in "Xiem" banana peel powder using response surface methodology. J Appl Biol Biotech 2021; 9(06):56-62. 